\title{
Vitamin D and activated vitamin D in tuberculosis in equatorial Malaysia: a prospective clinical study
}

Anna P. Ralph ${ }^{1,2,3^{*}}$, Muhammad Redzwan S. Rashid Ali ${ }^{4}$, Timothy William ${ }^{3,5,6}$, Kim Piera' ${ }^{1}$, Uma Parameswaran ${ }^{3}$, Elspeth Bird ${ }^{3}$, Christopher S. Wilkes ${ }^{3}$, Wai Khew Lee ${ }^{7}$, Tsin Wen Yeo ${ }^{1,7,8}$ and Nicholas M. Anstey $y^{1,2,3}$

\begin{abstract}
Background: Vitamin D deficiency (low plasma 25-hydroxyvitamin D [25D] concentration) is often reported in tuberculosis. Adjunctive vitamin $\mathrm{D}$ has been tested for its potential to improve treatment outcomes, but has proven largely ineffective. To better understand vitamin D in tuberculosis, we investigated determinants of 25D and its immunologically active form, 1,25-dihydroxyvitamin D (1,25D), their inter-relationship in tuberculosis, longitudinal changes and association with outcome.
\end{abstract}

Methods: In a prospective observational study of adults with smear-positive pulmonary tuberculosis in Sabah, Malaysia, we measured serial 25D, 1,25D, vitamin D-binding protein (VDBP), albumin, calcium, parathyroid hormone, chest x-ray, week 8 sputum smear/culture and end-of-treatment outcome. Healthy control subjects were enrolled for comparison.

Results: 1,25D was elevated in 172 adults with tuberculosis (mean 229.0 pmol/L, 95\% confidence interval: 215.4 242.6) compared with 95 controls $(153.9,138.4-169.4, p<0.001)$, directly proportional to radiological severity $(p<0$. 001), and fell rapidly within one week of treatment commencement. Tuberculosis patients with higher baseline 1,25D achieved significantly higher percentage weight gain over time, including when controlling for baseline weight, however persistently elevated 1,25D was associated with worse residual $x$-ray changes and lower end-oftreatment BMI. 1,25D was inversely associated with PTH ( $p<0.001)$, consistent with the extra-renal origin of the 1,25D. 25D did not differ between tuberculosis patients (mean $63.9 \mathrm{nmol} / \mathrm{L}, 95 \% \mathrm{Cl}: 60.6$ - 67.3) and controls (61.3, 57.2- 65.3, $p=0.24$ ), and was unassociated with outcomes. Among tuberculosis patients in multivariable analyses, sex, age and VDBP were associated with 25D, and age and albumin with 1,25D. 1,25-dihydroxyvitamin was not significantly asscociated with 25D. Vitamin D deficiency $<25 \mathrm{nmol} / \mathrm{L}$ was uncommon, occurring in only five TB patients; 1,25D was elevated in three of them.

Conclusions: In an equatorial setting, high extra-renal production of 1,25D was seen in tuberculosis, including in individuals with 25D in the deficient range; however, severe 25D deficiency was uncommon. Baseline elevation of 1,25D, a marker of macrophage activation, was associated with better weight gain but persistent elevation of 1,25D was associated with worse radiological and BMl outcomes. 1,25D warrants testing in larger datasets including TB patients less responsive to treatment, such as multi-drug resistant $\mathrm{TB}$, to test its utility as a marker of tuberculosis severity and treatment response.

Keywords: 25-hydroxyvitamin D, Cholecalciferol, 1,25-dihydroxyvitamin D, Calcitriol, Tuberculosis

\footnotetext{
* Correspondence: anna.ralph@menzies.edu.au

'Global and Tropical Health Division, Menzies School of Health Research,

Charles Darwin University, PO Box 41096, Casuarina, NT 0811, Australia

2Department of Medicine, Royal Darwin Hospital, Darwin, Northern Territory,

Australia

Full list of author information is available at the end of the article
} 


\section{Background}

Tuberculosis (TB) remains a leading global cause of morbidity and mortality [1]. Vitamin D metabolism is altered in tuberculosis [2, 3], and a number of studies have described vitamin D deficiency in active tuberculosis [35]. However, more recent studies from equatorial African settings have provided divergent results $[6,7]$. Thus it appears that while profound vitamin $\mathrm{D}$ deficiency may pose a risk for the development of active $\mathrm{TB}$, this effect is not observable in equatorial locations which are relatively protected from vitamin $\mathrm{D}$ deficiency.

Vitamin D deficiency is defined according to serum concentration of total (free and protein-bound) 25hydroxyvitamin $\mathrm{D}_{3}$ (25D, also termed cholecalciferol). Deficiency is common currently, partly because the thresholds cited for deficiency are not based on normal population distributions, and are now lower than in previous decades, as reviewed elsewhere [8]. The active form of vitamin $\mathrm{D}$ is 1,25-dihydroxycholecalciferol (1,25D, also termed calcitriol).1,25D can be produced in excess in tuberculosis occasionally resulting in hypercalcaemia [9-11], due to production of 1- $\alpha$ hydroxylase by activated macrophages [12] in an unregulated fashion [13]. Activated vitamin D has key immunomodulatory functions in the human anti-mycobacterial response [8, $12,14,15]$, so the ability of infected human host cells to generate and utilise adequate intracellular $1,25 \mathrm{D}$ is considered to be of major importance. Increased production of $1,25 \mathrm{D}$ in $\mathrm{TB}$ is integral to expression of an antimycobacterial peptide, stimulation of autophagy and autophagosome activity [14] and reduction in deleterious cell-mediated inflammatory responses [16].

These factors and other apparent associations between vitamin D and TB (e.g. seasonality [17]), have fuelled optimism that vitamin $\mathrm{D}$ adjunctive treatment may be beneficial in preventing or treating TB $[16,18,19]$. However, findings from trials in active $\mathrm{TB}$ have mostly been negative to date [20-24]. Alternative hypotheses may explain the apparent associations; e.g. vitamin D 'deficiency' could be a consequence of tuberculosis, since vitamin $\mathrm{D}$ behaves as a negative acute phase reactant in other situations such as surgery [25-27] and during immune restoration syndrome in TB-HIV co-infection [28].

No studies in which 25D and 1,25D have both been measured in TB have been reported to date. While $1,25 \mathrm{D}$ is the active hormone, its measurement has generally not been performed because of its reported short half-life, 1000 -fold lower concentration than 25D, because levels may rise in vitamin D deficiency in response to elevated PTH [29] and because systemic levels might not reflect true concentration at the intracellular level [30]. Also, in vitro studies show that immunological effects may correlate better with 25D concentrations [13]. Nevertheless, measurement of both serum 25D and
$1,25 \mathrm{D}$ would provide answers about the origins and consequences of low $25 \mathrm{D}$ in active TB. Speculation to date has included that $25 \mathrm{D}$ deficiency would result in $1,25 \mathrm{D}$ concentrations insufficient for optimal immunological responses [14], or that 25D deficiency may occur due to excessive conversion to 1,25D [31].

Our aims were to identify determinants of 25D and $1,25 \mathrm{D}$ concentrations in active tuberculosis, examine longitudinal changes in the absence of vitamin D supplementation, and explore relationships between 25D and $1,25 \mathrm{D}$ and with disease severity and TB outcomes. We therefore conducted a prospective study of adults with pulmonary TB in Sabah, Malaysia. We also recruited healthy volunteers for comparison.

\section{Methods}

\section{Setting}

This was a prospective observational study of smearpositive pulmonary tuberculosis (PTB) outpatients in Sabah, Malaysia. Kota Kinabalu is equatorial, latitude $6^{\circ}$ $\mathrm{N}$, with fairly consistent weather year round. Participants were enrolled at Luyang Tuberculosis Outpatient Clinic, Kota Kinabalu.

\section{Ethics, consent and permissions}

Eligible participants with PTB and healthy controls were required to provide written, informed consent after receiving verbal, written and pictorial explanations about the study. Consent was obtained from a parent/guardian for participants aged 15-17. Ethical approval was obtained from the Medical Research Ethics Committee, Malaysian Ministry of Health (NMRR-11-1051-10491), and the Human Research Ethics Committee of the Northern Territory Department of Health and Menzies School of Health Research, Australia (HREC-2010-1398).

\section{Participants}

Participants were eligible if they provided consent, had sputum smear-positive pulmonary $\mathrm{TB}$, were aged $\geq 15$ years, not pregnant, and had received $<7$ days' TB treatment. Smear-positive pulmonary TB was diagnosed on the basis of clinical and $\mathrm{x}$-ray assessment, and at least one sputum positive for acid fast bacilli (AFB) on ZiehlNeelsen stain. Culture confirmation of Mycobacterium tuberculosis was obtained [32]; patients in whom TB was confidently excluded (e.g. non-tuberculous mycobacteria or negative culture with inadequate clinical evidence of TB) were excluded from analyses. Healthy controls, sought from among family members of TB patients, blood donors, and clinic staff members, were eligible to volunteer if they provided consent, were aged $\geq 18$ years, not pregnant, and had no intercurrent illness including cough or asthma. Any TB contacts had mantoux testing performed followed by chest $\mathrm{x}$-ray if positive, and 
exclusion as a healthy control if TB or other disease was identified. Participants lost to study follow up were reengaged whenever possible if they attended the TB clinic to collect medication or for clinical review. For participants who switched treatment clinics, multiple contact attempts were made by telephone and text message to the individual or their next of kin to ask them to resume study participation at Luyang clinic and to ensure they were adhering to TB treatment; participants who defaulted from TB treatment altogether were similarly contacted multiple times by study staff, in addition to activation of the routine defaulter tracing service provided by Luyang clinic.

\section{Procedures}

Blood was collected for 25D, 1,25D, parathyroid hormone $(\mathrm{PTH})$, calcium, albumin and vitamin $\mathrm{D}$ binding protein once in controls and at serial time points in tuberculosis patients (weeks $0,1,8$, and 24; week 1 blood samples were introduced later and hence have more missing values). HIV was additionally tested in TB patients [33]. After collection, blood was separated immediately at the on-site laboratory, by centrifugation at $2000 \mathrm{rpm}$ for $6 \mathrm{~min}$. Aliquots were promptly frozen at $-80{ }^{\circ} \mathrm{C}$ and batched for transportation to the reference laboratories at regular intervals. Assays used were: 25$\mathrm{OH}$ vitamin $\mathrm{D}_{2}$ and $25-\mathrm{OH}$ vitamin $\mathrm{D}_{3}$ : liquid chromatography-tandem mass spectrometry; 1,25 dihydroxyvitamin D: IDS-iSYS immunopurification and quantitative determination; vitamin D-binding protein: Immunodiagnostik Enzyme linked immunosorbent assay; PTH: Roche cobas electrochemiluminescence immunoassay; calcium and albumin: Abbott ARCHITECT c16000 analyzer (Abbott Diagnostics, Chicago, IL, USA). Chest $\mathrm{x}$-rays were taken in TB patients at enrolment, 8 weeks and 24 weeks, and read by a single investigator (APR) blinded to blood results using a previously validated score [34].

\section{Definitions}

Ethnicity was described as Malaysian (Malaysian-born people of Malay, Chinese and/or Indian descent), and non-Malaysian (Indonesian or Filipino). The threshold for adequate (sufficient) 25D was considered to be $\geq 50 \mathrm{nmol} / \mathrm{L}$ [35]. Normal reference ranges for other assays provided by the respective laboratories were: $1,25 \mathrm{D}$ : 50-160 pmol/L, PTH: 0.8-5.5 pmol/L, corrected calcium: 2.10-2.55 mmol/L, albumin: $39-50 \mathrm{~g} / \mathrm{L}$.

\section{Statistics}

Data were analysed using Stata ${ }^{\mathrm{TM}}$ 14.0. (Stata Corp, College Station, Texas, USA). No sample size calculation was required for this observational study design. Continuous variables were compared using Student's T test or Wilcoxon Rank Sum test. Normal transformations were applied where necessary (PTH: log; VDBP: squareroot). Categorical variables were compared using Chisquared or Fisher's Exact test, as appropriate. Multivariable linear or logistic regression models were developed using a forwards stepwise approach; variables showing potential association with the dependent variable or those considered plausibly relevant (e.g. age, sex, body mass index $[\mathrm{BMI}]$ ), were included in final models. The goodness of fit of logistic regression models was assessed using the Hosmer-Lemeshow test. For linear regression models, residuals were examined to ensure that relevant assumptions were met. For longitudinal data, analyses were restricted to individuals with paired data (baseline result and at the follow up time point), and compared using paired t-tests.

\section{Results}

After exclusions (Fig. 1), 172 sequential, consenting participants were included for analysis. Most (148; 84.1\%) had received $\leq 2$ doses of TB treatment prior to enrolment and none had received $>7$ doses. Other results from this patient cohort have been published showing none had multidrug-resistant TB [32] and 3 (1.7\%) had HIV co-infection [33]. Men were over-represented, were more likely to smoke, had a tendency toward higher baseline smear grade, and had more extensive radiological involvement (Table 1). Greater disease severity in men remained evident after controlling for smoking (data not shown). Ninety six healthy controls were enrolled; they were more likely to be Malaysian, female, non-smokers and have higher BMI than TB patients ( $p$ $<0.0001$ in each instance); see Table 1 . These factors were controlled for in multivariable analyses.

The median time of freezing of blood samples after collection was $15.0 \mathrm{~min}$, with $275 / 320$ (85.9\%) samples being frozen within $30 \mathrm{~min}$. Results were not available for all assays at all time-points, due to failures of patients to attend appointments, inadequate aliquots for all assays, or laboratory errors. Losses to follow up are shown in Fig. 1.

\section{Tuberculosis versus controls}

At enrolment, mean total 1,25-dihydroxyvitamin D was elevated in tuberculosis (mean $229.0 \mathrm{pmol} / \mathrm{L}, 95 \% \mathrm{CI}$ 215.4-242.6) compared with controls (153.9, 138.4-169.4, $p<0.001)$. Calcium was also significantly higher, $\mathrm{PTH}$ and albumin were significantly lower, and VDBP did not differ (Table 2; Fig. 2). Mean total 25D did not differ between TB patients and healthy controls in univariable analysis nor when controlling for sex, age, BMI and ethnicity (Table 2). Among both TB patients and controls, males had significantly higher 25D than females (Table 2 and Fig. 3e). 


\section{Recruitment period: \\ 04/07/2012-03/07/2014 \\ 395 individuals with new TB \\ 238 males (60.3\%)}

219 excluded

- 128 not consenting

- 79 ineligible (58 referred out, 9 on TB treatment for $>5$ days, 6 not referred to research nurse, 4 aged $<15 \mathrm{yrs}, 2$ not smear + pulmonary TB)

- 9 too elderly or sick

- 3 pregnant

176 enrolled

\section{4 excluded}

- 3 Non-tuberculous mycobacterium in sputum, no evidence of TB

- 1 culture negative, no evidence of TB

172 analyzed at baseline

$102(59.3 \%)$ male

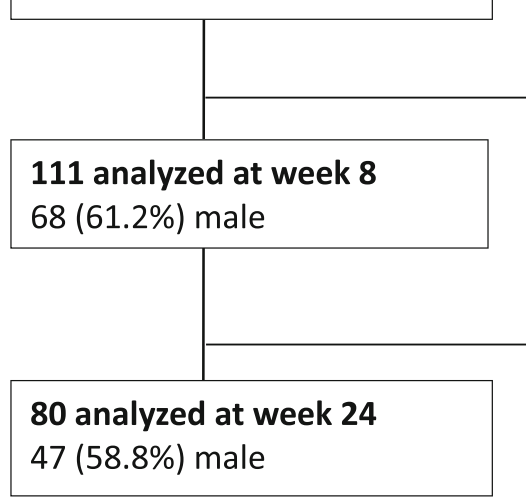

61 lost to follow up from study (defaulted or withdrew consent)

$\mathbf{3 0}$ lost to follow up from study (defaulted or withdrew consent)

Fig. 1 Study diagram

\section{Factors associated with 1,25-dihydroxyvitamin $D$ and 25-hydroxyvitamin $D$ in TB}

Factors associated with $1,25 \mathrm{D}$ and $25 \mathrm{D}$ are shown in Table 3 and Figs. 3 and 4. 1,25D was strongly associated with radiological severity (Fig. 4a), and inversely associated with PTH (Fig. 4b). There was no statistically significant relationship between $25 \mathrm{D}$ and $1,25 \mathrm{D}(p=0.08$; Fig. 4c). Mean 1,25D concentration was lower (median $159 \mathrm{pmol} / \mathrm{L}$, range 27-346) in those with severe vitamin D deficiency $<25 \mathrm{nmol} / \mathrm{L}$ compared to those with a level $>25 \mathrm{nmol} / \mathrm{L}$ (median $218 \mathrm{pg} / \mathrm{mL}$, range 106-456), but this was not statistically significant $p=0.16$. Severe vitamin $\mathrm{D}$ deficiency did not preclude a high $1,25 \mathrm{D}$ concentration; for example, one male with severe vitamin D deficiency (serum 25D concentration $8.0 \mathrm{nmol} / \mathrm{L}$ ) had a corresponding 1,25D concentration of $346 \mathrm{pmol} / \mathrm{L}$ (Fig. 4c).

\section{Longitudinal changes}

Among tuberculosis patients, $1,25 \mathrm{D}$ decreased rapidly after institution of treatment, reaching the normal reference range by week 1 (Fig. 2b). Albumin rose significantly over time, and VDBP concentration did not change (Fig. 2c and d). A small increase in total 25D 
Table 1 Baseline characteristics

\begin{tabular}{lll}
\hline & Tuberculosis & Controls \\
\hline Number & 172 & 95 \\
Age in years: median (range) & $29(15-70)$ & $28(18-66)$ \\
Male: no. (\%) & $102(59.3 \%)$ & $34(35.8 \%)$ \\
Malaysian: no. (\%) & $113 / 172(65.7 \%)$ & $86 / 95(90.5 \%)$ \\
Current or ex-smoker & $88 / 172(51.2 \%)$ & $27 / 95(28.4 \%)$ \\
$\quad$ Males & $80 / 102(78.4 \%)$ & $23 / 34(67.7 \%)$ \\
Females & $8 / 70(11.4 \%)$, & $4 / 61(6.6 \%)$ \\
Body mass index (kg/m²): & $18.0(9.95-31.1)$ & $24.2(16.1-37.2)$ \\
mean (range) & & \\
HIV positive: no. (\%) & $3 / 172(1.7 \%)$ & - \\
Microscopy grade $\geq 2$ plus: & $118 / 175(67.4 \%)$ & - \\
no. (\%) & & \\
Males & $75 / 103(72.8 \%)$ & \\
Females & $43 / 72(59.7 \%)$ & \\
Time to culture positivity in days: & $13.5(3.9)$ & \\
mean (standard deviation) & & \\
Radiological severity: & & \\
Cavitary disease & $94 / 144(65.2 \%)$ \\
Score: mean (standard deviation) & $69.9(34.5)$ & - \\
$\quad$ Males & $74.8(33.7)$ & \\
$\quad$ Females & $61.4(35.4)$ & \\
\hline
\end{tabular}

occurred among 81 individuals with paired data during treatment (Fig. 2a); 25D increased from 68.0 at week 0 to 71.7 at week $24, p=0.049$.

\section{Associations with microbiological and clinical outcomes}

TB treatment outcomes were recorded for 159 individuals. One death and no failures were reported (cured/ completed: 112 (70.4\%), defaulted: 23 (14.5\%), transferred $23(14.5 \%)$, died $1(0.6 \%))$. At 2 months, 8 were reported culture positive and 11 were smear positive. The small numbers limited the ability to explore associations; no associations with 2-month culture conversion were identified. In testing associations with other outcome measures (percentage lung affected on x-ray, overall x-ray score and BMI at treatment completion), 25D was unassociated with treatment outcome. However, $1,25 \mathrm{D}$ did show associations with $\mathrm{x}$-ray and BMI outcomes. Individuals with higher baseline 1,25D achieved significantly higher percentage weight gain over time (Fig. 5), including when controlling for baseline weight (itself directly proportional to \%weight gain); weight gain by treatment completion was $3.2 \%$ greater for every $1 \mathrm{pmol} / \mathrm{L}$ increase in baseline $1,25 \mathrm{D}(p=0.008)$. A similar statistically significant association was found for BMI. A failure of $1,25 \mathrm{D}$ to normalise to less than $150 \mathrm{pmol} / \mathrm{L}$ after week 0 was associated with poorer final radiological outcome (Table 4). Persistent elevation in 1,25D at week 24 was also associated with poorer weight gain (BMI 18.2 versus $20.4 \mathrm{~kg} / \mathrm{m} 2, p=0.008)$. These associations were not explained by a relationship between baseline $1,25 \mathrm{D}$ and baseline or final disease severity (Fig. 4a), since elevation in $1,25 \mathrm{D}>150 \mathrm{pmol} / \mathrm{L}$ at baseline was not associated with these measures.

\section{Discussion}

Among people with active pulmonary TB, we found that systemic concentrations of total activated vitamin $D$ $(1,25 \mathrm{D})$ were very high, in direct proportion to disease severity, fell rapidly with institution of effective therapy, and were more likely to remain elevated above 150 $\mathrm{pmol} / \mathrm{L}$ in individuals with persisting radiological changes and poorer BMI attainment. High 1,25D was associated with suppressed PTH responses as expected, in keeping with macrophage-derived $1 \alpha$-hydroxylase as the source of the elevated $1,25 \mathrm{D}$. We cannot exclude

Table 2 Blood test results among tuberculosis patients at diagnosis and controls

\begin{tabular}{|c|c|c|c|c|c|c|}
\hline & \multirow[t]{2}{*}{ Tuberculosis } & \multirow[t]{2}{*}{ Controls } & \multicolumn{2}{|c|}{$\begin{array}{l}\text { Univariable analyses, } \\
\text { TB vs controls }\end{array}$} & \multicolumn{2}{|c|}{$\begin{array}{l}\text { Multivariable analyses, } \\
\text { TB vs controls }\end{array}$} \\
\hline & & & $\beta$ coefficient & $\overline{P \text { value }}$ & $\beta$ coefficient & $P$ value \\
\hline \multicolumn{7}{|l|}{ Total 25-hydroxyvitamin D (nmol/L): mean (95\% Cl) } \\
\hline All & $63.9(60.6-67.3)$ & $61.4(57.4-65.3)$ & 2.55 & 0.350 & -4.11 & 0.238 \\
\hline Males & $69.9(65.5-74.3)$ & $70.1(64.4-75.9)$ & & & & \\
\hline Females & $55.2(50.6-59.8)$ & $56.2(51.4-61.0)$ & & & & \\
\hline Vitamin D deficiency (25D < 50 nmol/L) & $46 / 167(27.5 \%)$ & $23 / 92(25.0 \%)$ & & 0.657 & & \\
\hline Total 1,25-dihydroxyvitamin D (pmol/): mean (95\% Cl) & $229.0(215.4-242.6)$ & $153.8(138.6-169.0)$ & 75.20 & $<0.001$ & 63.5 & $<0.001$ \\
\hline Parathyroid hormone (pmol/L): median (IQR) & $1.8(1.1-2.5)$ & $3.6(3.0-4.7)$ & -0.76 & $<0.001$ & -0.71 & $<0.001$ \\
\hline Calcium: mean (95\% Cl) & $2.42(2.40-2.44)$ & $2.34(2.32-2.36)$ & 0.08 & $<0.001$ & 0.09 & $<0.001$ \\
\hline Albumin: mean (95\% Cl) & $35.7(35.1-36.3)$ & $42.4(41.7-43.1)$ & -6.73 & $<0.001$ & -5.64 & $<0.001$ \\
\hline Vitamin D binding protein (mcg/mL): median (IQR) & $128.0(\mathrm{IQR} 66.6-198.3)$ & $131.6(66.0-178.4)$ & 16.30 & 0.301 & 5.06 & 0.818 \\
\hline
\end{tabular}

All models include age, sex, ethnicity, BMI. Transformations were applied to achieve a normal distribution for PTH (log) and VDBP (square root) 

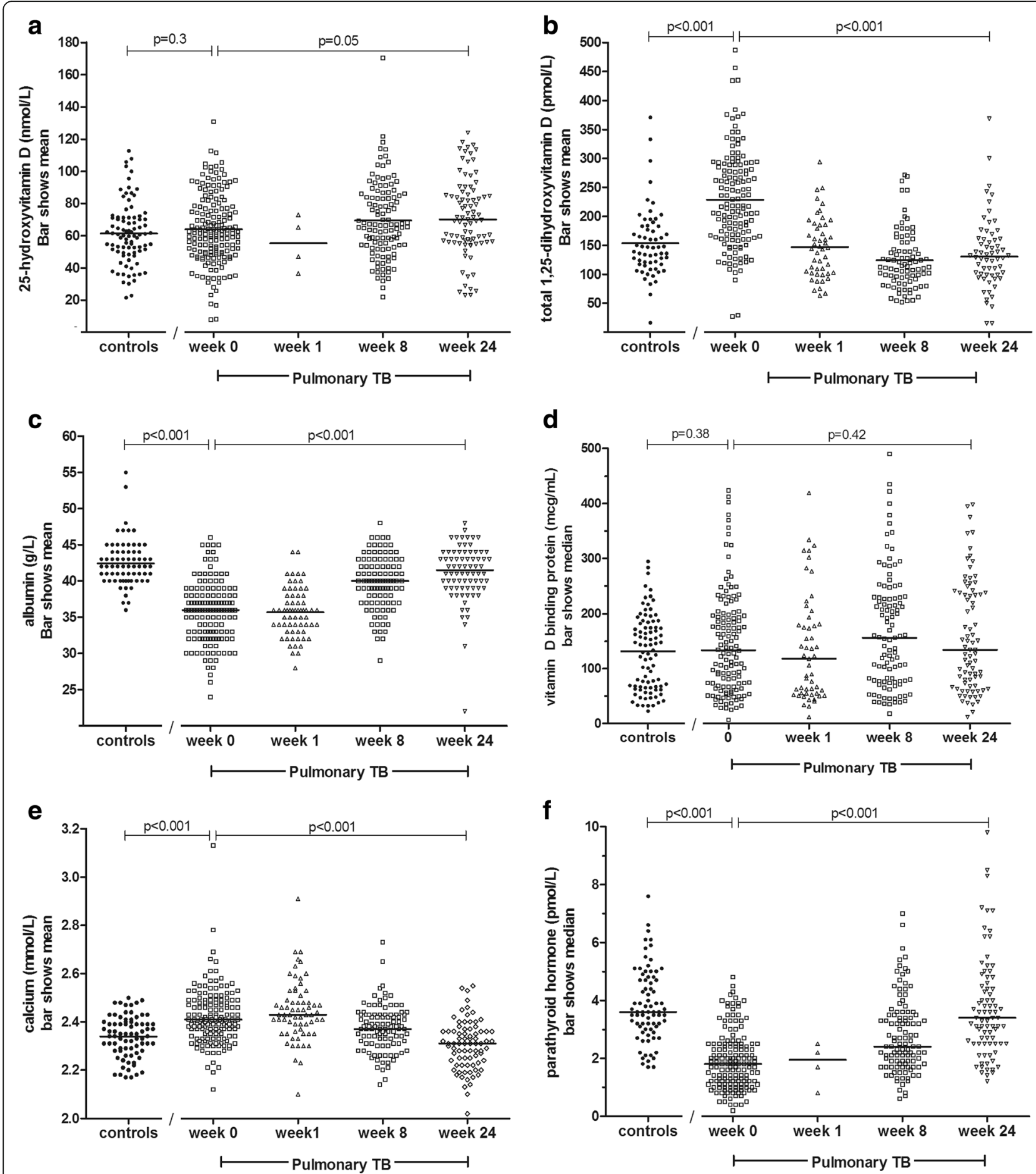

Fig. 2 Blood test results at baseline and during follow up in TB patients and healthy controls. Legend: An individual data point is shown for each available test result. Longitudinal statistical comparisons of results are restricted to individuals with paired data. (a) 25-hydroxyvitamin D (b) 1,25dihydroxyvitamin $\mathrm{D}(\mathbf{c})$ albumin $(\mathbf{d})$ vitamin $\mathrm{D}$ binding protein $(\mathbf{e})$ calcium $(\mathbf{f})$ parathyroid hormone

that the sudden fall in $1,25 \mathrm{D}$ with treatment was due to a drug effect; isoniazid and rifampicin can both affect 25D concentration [36] although an effect on 1,25D has not been reported. However, the associations with outcomes suggest that even if this were a factor, it is not the sole explanation.

Vitamin D deficiency was not a characteristic of TB in this tropical setting, and was unassociated with $\mathrm{TB}$ 


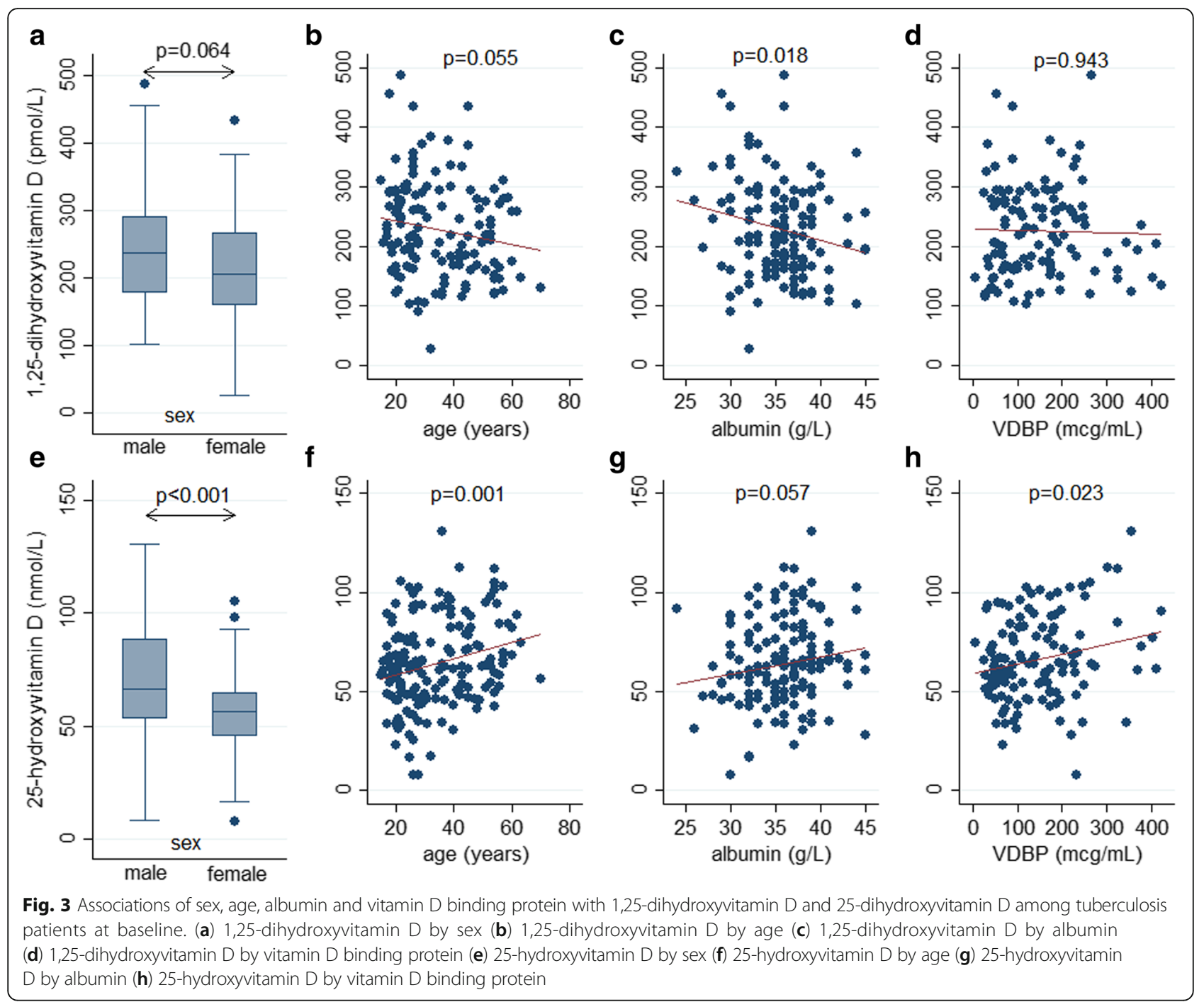

outcomes. A similar lack of association has also been shown in a study of Malawian adults with TB [37]. 1,25D was not closely linked to serum 25D concentration.

These findings contrast with some previous results from non-tropical settings, where 25D concentration is frequently lower in active TB then controls [3-5] and where there may be failure to mount an adequate 1,25D response [38]. Our findings support the hypothesis that individuals who have adequate vitamin $\mathrm{D}$ stores at the time of onset of active TB are able to produce $1,25 \mathrm{D}$ from extra-renal sources in excess. It is plausible that a threshold effect may occur whereby serum 25D concentrations in the very deficient range, of which we saw little, would indeed not support the high 1,25D production shown in our patients. This could potentially explain differences in findings reported by Witt et al., of low 1,25D in TB [38].

Elevated 1,25D has been found previously in TB patients [31] but in that study, 25D was not measured, so the authors speculated that elevated $1,25 \mathrm{D}$ could lead to substrate (25D) depletion, and hence that vitamin D supplementation could be worthwhile. We have now shown that vitamin $\mathrm{D}$ substrate (25D), present at concentrations a magnitude higher than $1,25 \mathrm{D}$, is not depleted in TB patients by conversion to $1,25 \mathrm{D}$.

$1,25 \mathrm{D}$ concentration can be considered a proxy for macrophage activation in this setting. Our finding that higher baseline 1,25D may be advantageous, given its association with ultimate weight gain, could reflect an advantage to the host provided by a robust macrophage immune response at baseline. Also, 1,25D has immunomodulatory properties which may mitigate lung damage, such as inhibition of Th1 cytokines including interferon gamma [8], and suppression of metalloproteinases [39]. An alternative explanation is that a high disease burden at baseline, and therefore high 1,25D levels (Fig. 4a), is associated with greater relative weight gain with treatment; however, this is less likely since baseline weight/ 
Table 3 Factors associated with 1,25-hydroxyvitamin D and 25-hydroxyvitamin D in tuberculosis patients and control subjects

\begin{tabular}{|c|c|c|c|c|c|c|c|c|}
\hline & \multirow{2}{*}{\multicolumn{2}{|c|}{$\frac{\text { 25-hydroxyvitamin D }}{\text { Univariable analyses }}$}} & \multirow{2}{*}{\multicolumn{2}{|c|}{ Multivariable analyses }} & \multirow{2}{*}{\multicolumn{2}{|c|}{$\frac{1,25 \text {-hydroxyvitamin } \mathrm{D}}{\text { Univariable analyses }}$}} & \multirow{2}{*}{\multicolumn{2}{|c|}{ Multivariable analyses }} \\
\hline & & & & & & & & \\
\hline & $\beta$ coefficient & $P$ value & $\beta$ coefficient & $P$ value & $\beta$ coefficient & $P$ value & $\beta$ coefficient & $P$ value \\
\hline \multicolumn{9}{|l|}{ Tuberculosis } \\
\hline Sex $(0=$ female, $1=$ male $)$ & 14.65 & $<0.001$ & -12.80 & 0.007 & 25.85 & 0.064 & -34.37 & 0.057 \\
\hline Age & 0.41 & 0.001 & 0.32 & 0.024 & -0.98 & 0.055 & -1.83 & 0.001 \\
\hline BMI & 0.31 & 0.561 & - & - & -3.59 & 0.111 & - & - \\
\hline Smoking ( $0=$ no, $1=$ yes $)$ & 12.91 & $<0.001$ & 4.84 & 0.062 & 5.13 & 0.711 & -7.66 & 0.468 \\
\hline Albumin & 0.86 & 0.057 & 0.46 & 0.356 & -4.14 & 0.018 & -4.52 & 0.021 \\
\hline VDBP & 0.04 & 0.023 & 0.03 & 0.037 & 0.00 & 0.943 & 0.00 & 0.514 \\
\hline X-ray severity score & -0.09 & 0.125 & -0.11 & 0.054 & 0.97 & $<0.001$ & 0.68 & 0.003 \\
\hline \multicolumn{9}{|l|}{ Controls } \\
\hline Sex $(0=$ female, $1=$ male $)$ & 13.92 & 0.001 & -8.64 & 0.077 & 1.00 & 0.744 & -35.40 & 0.23 \\
\hline Age & 0.42 & 0.012 & 0.04 & 0.045 & -1.14 & 0.062 & -1.69 & 0.08 \\
\hline BMI & -0.21 & 0.637 & - & - & -1.40 & 0.453 & - & - \\
\hline Smoking ( $0=$ no, $1=$ yes $)$ & 12.15 & 0.009 & 3.19 & 0.471 & 1.00 & 0.497 & 2.40 & 0.92 \\
\hline Albumin & 0.57 & 0.424 & 0.13 & 0.858 & 0.55 & 0.885 & -3.92 & 0.35 \\
\hline VDBP & 0.03 & 0.175 & 0.00 & 0.778 & 0.07 & 0.389 & 0.00 & 0.17 \\
\hline
\end{tabular}

$P$ values $\leq 0.05$ shown in bold

Multivariable models include sex, age, smoking, albumin, VDBP and for TB patients, $x$-ray score

A transformation was applied to achieve a normal distribution for VDBP (square root)

a

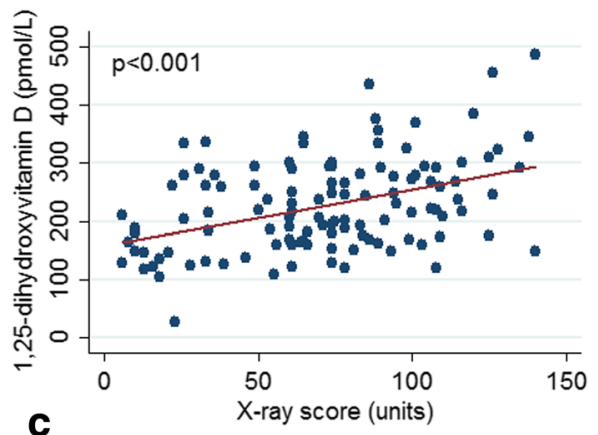

$\mathbf{C}$

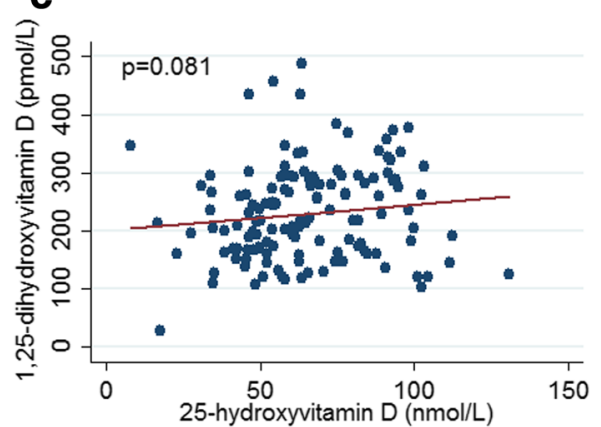

b

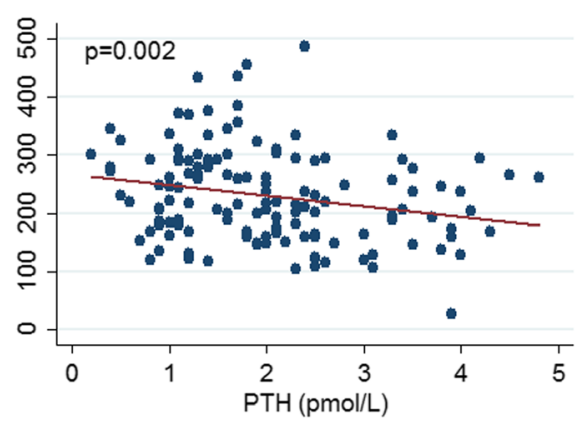

Fig. 4 Relationships between 1,25-dihydoxyvitamin D and radiological severity, parathyroid hormone and 25-hydroxyvitamin D at baseline. (a) 1,25-dihydroxyvitamin D by x-ray score (b) 1,25-dihydroxyvitamin D by parathyroid hormone (c) 1,25-dihydroxyvitamin D by 25-hydroxyvitamin D 


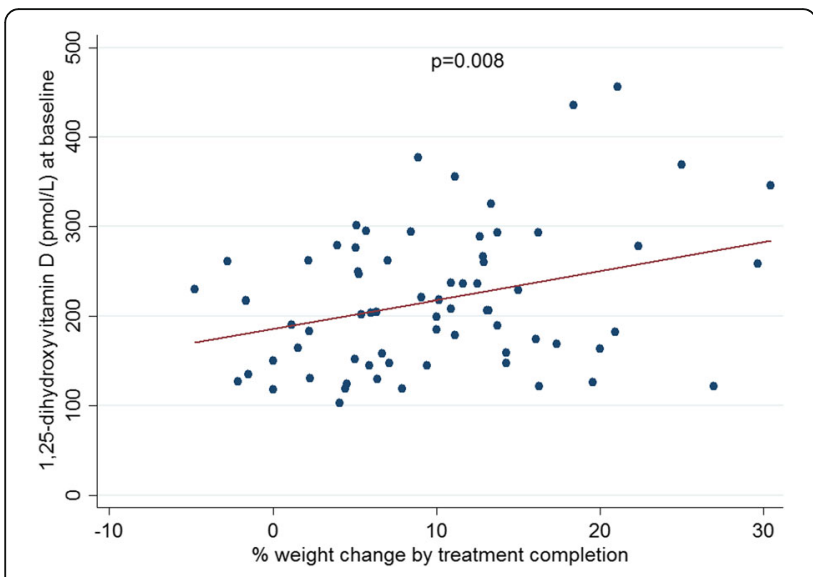

Fig. 5 Relationship between baseline 1,25-dihydroxyvitamin D and percentage weight gain during tuberculosis treatment

BMI were unassociated with $1,25 \mathrm{D}$, and baseline weight was included in the model testing the association between $1,25 \mathrm{D}$ and weight gain. The finding that persistent elevation in $1,25 \mathrm{D}$ was indicative of a poorer radiological outcome fits with a hypothesis that ongoing macrophage activation in the lung contributes to persisting inflammation and lung damage.

One of our hypotheses was that 25D may behave as a negative acute phase reactant in $\mathrm{TB}$, as has been documented in other conditions [25-28], due to proteinbinding and the association between low protein and inflammatory disease states. However, these data do not strongly support this - while 25D was associated with concentrations of binding proteins, VDBP did not differ between TB and controls and did not rise over time, and the spontaneous rise in 25D with treatment, which has been shown previously $[22,40]$, was slight.

Limitations of this study include that the control subjects were not matched on sex,ethnicity or BMI, but rather, represented members of society who agreed to participate. We sought controls who would resemble the

Table 4 Relationship between a persistent elevation in 1,25D and radiological severity at treatment completion

\begin{tabular}{llll}
\hline & $\begin{array}{l}1,25 \mathrm{D} \leq 150 \\
\text { pmol/L } \\
\begin{array}{l}\text { X-ray score at treatment completion } \\
\text { (median, range) }\end{array}\end{array}$ & $\begin{array}{l}1,25 \mathrm{D}>150 \\
\mathrm{pmol} / \mathrm{L}\end{array}$ & \\
\hline week 0 & $10(1-101)$ & $17(0-115)$ & 0.460 \\
week 1 & $8.5(2-68)$ & $33.5(1-83)$ & 0.075 \\
week 8 & $12.0(0-101)$ & $36.5(5-115)$ & 0.033 \\
week 24 & $11.0(0-101)$ & $42.0(2-115)$ & 0.002 \\
Pooled results (any week & $11.0(0-101)$ & $42(1-115)$ & $<0.001$
\end{tabular}

after enrolment)

Results show that $1,25 \mathrm{D}>150 \mathrm{pmol} / \mathrm{L}$ at week 0 was unassociated with final radiological outcome, but persistent elevation in $1,25 \mathrm{D}>150 \mathrm{pmol} / \mathrm{L}$ at weeks 1,8 or 24 was associated with worse final radiological outcome, i.e. a higher $\mathrm{x}$-ray score
TB patients by including family members, but inevitable differences were evident between the groups. While the multivariable models controlled for these differences, this may still limit conclusions that can be drawn. Missing data occurred for some measures at given time points, chiefly due to patient losses to follow up (Fig. 1); this could result in bias, but the overall effect would have been to diminish power to detect differences between groups and over time. Our endpoints regarding $\mathrm{TB}$ outcomes were clinical and radiological rather than more robust microbiological endpoints, due to the homogeneity of microbiological outcomes; also, we were unable to include long-term TB relapse as an outcome. We did not measure UV exposure or diet, hence changes in these may have contributed to the longitudinal increase in total 25D concentration. However, diet in this setting contributes only marginally to vitamin D intake, and all participants were ambulant outpatients at enrolment mostly still engaged in their usual employment, so UV exposure is unlikely to have changed substantially over time. We did not have $25 \mathrm{D}$ or $1,25 \mathrm{D}$ concentrations prior to onset of TB for obvious reasons; such prospective data would provide clarity on how perturbation in 25D metabolism relates to the onset of active infection. Also, 25D or 1,25D measures were made from peripheral blood samples, not the intracellular compartment, but it is likely that high plasma $1,25 \mathrm{D}$ concentration is reflected in high intracelluluar $1,25 \mathrm{D}$ bioavailability.

\section{Conclusions}

Our findings show the relationship between 25D and $1,25 \mathrm{D}$ in active tuberculosis, and indicate that extrarenal production of $1,25 \mathrm{D}$ was high, and was able to occur despite 25D being in the deficient range. Ongoing elevation of $1,25 \mathrm{D}$, a marker of macrophage activation, was associated with worse lung radiological outcomes. $1,25 \mathrm{D}$ warrants testing in larger datasets including TB patients less responsive to treatment, such as people with multi-drug resistant $\mathrm{TB}$, to assess its utility as a marker of tuberculosis severity and treatment response.

\section{Acknowledgements}

We are very grateful to Kelly Nestor, Ann Wee, Thecla Tasius, Florena Maidik and Sharon Nestor for enrolling the participants; and all the staff at Luyang Outpatient Clinic particularly Dr Eman Farhad, Dr Maryam Amaleena, Suzie Taylor, Jenny Omar and Dr Elissa Soh for supporting the project. We also thank the Ministry of Health, Malaysia for allowing the study to be conducted, and the Sabah State Health Department and Clinical Research Centre of Queen Elizabeth Hospital for general assistance.

\section{Funding}

This study was funded by the National Health and Medical Research Council (NHMRC) of Australia (Grant 605806 and fellowships 1016567 [APR] and 1042072 [NMA]).

Availability of data and materials

Data available on request. 


\section{Authors' contributions}

APR participated in study design, implementation and analysis and wrote the first draft of the paper; MRSRA implemented the study including enrolling participants; TW participated in study design and implementation; KP managed laboratory procedures and undertook assays; UP, EB and CSW enrolled participants; WKL and TWY provided clinical oversight and contributed to study implementation; NMA participated in study design, implementation and analysis. All authors read and approved the manuscript.

\section{Competing interests}

The authors declare that they have no competing interests.

\section{Consent for publication}

Not required.

\section{Ethics approval and consent to participate}

Ethical approval was obtained from the Medical Research Ethics Committee, Malaysian Ministry of Health (NMRR-11-1051-10491), and the Human Research Ethics Committee of the Northern Territory Department of Health and Menzies School of Health Research, Australia (HREC-2010-1398). All eligible participants provided written, informed consent. Consent was obtained from a parent/guardian for participants aged 15-17 years.

\section{Publisher's Note}

Springer Nature remains neutral with regard to jurisdictional claims in published maps and institutional affiliations.

\section{Author details \\ ${ }^{1}$ Global and Tropical Health Division, Menzies School of Health Research, Charles Darwin University, PO Box 41096, Casuarina, NT 0811, Australia. 2Department of Medicine, Royal Darwin Hospital, Darwin, Northern Territory, Australia. ${ }^{3}$ Infectious Diseases Society Sabah-Menzies School of Health Research Clinical Research Unit, Kota Kinabalu, Sabah, Malaysia. ${ }^{4}$ Department of Respiratory Medicine, Queen Elizabeth Hospital, Kota Kinabalu, Sabah, Malaysia. ${ }^{5}$ Jesselton Medical Centre, Kota Kinabalu, Sabah Infectious Diseases Unit, Clinical Research Centre, Queen Elizabeth Hospital, Kota Kinabalu, Sabah, Malaysia. ${ }^{6}$ Clinical Research Centre, Queen Elizabeth Hospital, Kota Kinabalu, Sabah, Malaysia. 'Luyang Outpatient Clinic, Kota Kinabalu, Sabah, Malaysia. ${ }^{8}$ Lee Kong Chian School of Medicine, Nanyang Technological University, Singapore, Singapore.}

Received: 24 September 2016 Accepted: 8 March 2017

Published online: 27 April 2017

\section{References}

1. World Health Organization. Global Tuberculosis Control, 2016. World Health Organization; 2016. http://www.who.int/tb/publications/global_report/en/. Accessed 22 Apr 2017.

2. Davies PD, Church HA, Bovornkitti S, Charumilind A, Byrachandra S. Altered vitamin D homeostasis in tuberculosis. Int Med Thailand. 1988;4:45-7.

3. Sita-Lumsden A, Lapthorn G, Swaminathan R, Milburn HJ. Reactivation of tuberculosis and vitamin D deficiency: the contribution of diet and exposure to sunlight. Thorax. 2007;62(11):1003-7.

4. Nnoaham KE, Clarke A. Low serum vitamin D levels and tuberculosis: a systematic review and meta-analysis. Int J Epidemiol. 2008;37(1):113-9.

5. Friis $\mathrm{H}$, Range N, Pedersen ML, Molgaard C, Changalucha J, Krarup H, Magnussen P, Soborg C, Andersen AB. Hypovitaminosis D is common among pulmonary tuberculosis patients in Tanzania but is not explained by the acute phase response. J Nutr. 2008;138(12):2474-80.

6. Conesa-Botella A, Goovaerts O, Massinga-Loembe M, Worodria W, Mazakpwe D, Luzinda K, Mayanja-Kizza H, Colebunders R, Kestens L, Group TIS. Low prevalence of vitamin D deficiency in Ugandan HIV-infected patients with and without tuberculosis. Int J Tuberc Lung Dis. 2012;16(11): 1517-21.

7. Owolabi O, Agbla S, Owiafe P, Donkor S, Togun T, Sillah AK, Ota MO, Sutherland JS. Elevated serum 25-hydroxy $(\mathrm{OH})$ vitamin D levels are associated with risk of TB progression in Gambian adults. Tuberculosis (Edinb). 2016;98:86-91.

8. Ralph AP, Lucas RM, Norval M. Vitamin D and solar ultraviolet radiation in the risk and treatment of tuberculosis. Lancet Infect Dis. 2013;13(1):77-88.
9. Davies PD, Church HA, Brown RC, Woodhead JS. Raised serum calcium in tuberculosis patients in Africa. Eur J Respir Dis. 1987;71(5):341-4.

10. Deniz O, Tozkoparan E, Yonem A, Ciftci F, Bozkanat E, Cakir E, Ozcan O, Narin Y, Bilgic H, Ekiz K, et al. Low parathormone levels and hypercalcaemia in patients with pulmonary tuberculosis: relation to radiological extent of disease and tuberculin skin test. Int J Tuberc Lung Dis. 2005;9(3):317-21.

11. Liam CK, Lim KH, Srinivas P, Poi PJ. Hypercalcaemia in patients with newly diagnosed tuberculosis in Malaysia. Int J Tuberc Lung Dis. 1998;2(10):818-23.

12. Coussens AK, Martineau AR, Wilkinson RJ. Anti-Inflammatory and Antimicrobial Actions of Vitamin D in Combating TB/HIV. Scientifica. 2014; 2014:903680

13. Adams JS, Rafison B, Witzel S, Reyes RE, Shieh A, Chun R, Zavala K, Hewison M, Liu PT. Regulation of the extrarenal CYP27B1-hydroxylase. J Steroid Biochem Mol Biol. 2014;144 Pt A:22-27.

14. Liu PT, Stenger S, Li H, Wenzel L, Tan BH, Krutzik SR, Ochoa MT, Schauber J, Wu K, Meinken C, et al. Toll-like receptor triggering of a vitamin D-mediated human antimicrobial response. Science. 2006;311(5768):1770-3.

15. Harishankar M, Afsal K, Banurekha W, Meenakshi N, Selvaraj P. 1,25Dihydroxy vitamin $D$ downregulates pro-inflammatory cytokine response in pulmonary tuberculosis. Int Immunopharmacol. 2014;23(1):148-52.

16. Ralph AP, Kelly PM, Anstey NM. L-arginine and vitamin D: novel adjunctive immunotherapies in tuberculosis. Trends Microbiol. 2008;16(7):336-44.

17. Maclachlan JH, Lavender CJ, Cowie BC. Effect of latitude on seasonality of tuberculosis, Australia, 2002-2011. Emerg Infect Dis. 2012;18(11):1879-81.

18. Martineau AR. Old wine in new bottles: vitamin D in the treatment and prevention of tuberculosis. Proc Nutr Soc. 2012;71(1):84-9.

19. Vieth R. Vitamin D nutrient to treat TB begs the prevention question. Lancet. 2011;377(9761):189-90.

20. Martineau AR, Timms PM, Bothamley GH, Hanifa Y, Islam K, Claxton AP, Packe GE, Moore-Gillon JC, Darmalingam M, Davidson RN, et al. High-dose vitamin $\mathrm{D}(3)$ during intensive-phase antimicrobial treatment of pulmonary tuberculosis: a double-blind randomised controlled trial. Lancet. 2011. 377(9761):242-50.

21. Ralph AP, Waramori G, Pontororing GJ, Kenangalem E, Wiguna A, Tjitra E, Sandjaja, Lolong DB, Yeo TW, Chatfield MD, et al. L-arginine and Vitamin D Adjunctive Therapies in Pulmonary Tuberculosis: A Randomised, DoubleBlind, Placebo-Controlled Trial. PLoS ONE. 2013;8(8):e70032.

22. Wejse C, Gomes VF, Rabna P, Gustafson P, Aaby P, Lisse IM, Andersen PL, Glerup $H$, Sodemann M. Vitamin D as supplementary treatment for tuberculosis: a double-blind, randomized, placebo-controlled trial. Am J Respir Crit Care Med. 2009;179(9):843-50.

23. Salahuddin N, Ali F, Hasan Z, Rao N, Aqeel M, Mahmood F. Vitamin D accelerates clinical recovery from tuberculosis: results of the SUCCINCT Study [Supplementary Cholecalciferol in recovery from tuberculosis]. A randomized, placebo-controlled, clinical trial of vitamin D supplementation in patients with pulmonary tuberculosis. BMC Infect Dis. 2013;13:22.

24. Daley P, Jagannathan V, John KR, Sarojini J, Latha A, Vieth R, Suzana S, Jeyaseelan L, Christopher DJ, Smieja M, et al. Adjunctive vitamin D for treatment of active tuberculosis in India: a randomised, double-blind, placebo-controlled trial. Lancet Infect Dis. 2015;15(5):528-34.

25. Louw JA, Werbeck A, Louw ME, Kotze TJ, Cooper R, Labadarios D. Blood vitamin concentrations during the acute-phase response. Crit Care Med. 1992;20(7):934-41.

26. Waldron JL, Ashby HL, Cornes MP, Bechervaise J, Razavi C, Thomas OL, Chugh S, Deshpande S, Ford C, Gama R. Vitamin D: a negative acute phase reactant. J Clin Pathol. 2013;66(7):620-2.

27. Reid D, Toole BJ, Knox S, Talwar D, Harten J, O'Reilly DS, Blackwell S, Kinsella J, McMillan DC, Wallace AM. The relation between acute changes in the systemic inflammatory response and plasma 25-hydroxyvitamin D concentrations after elective knee arthroplasty. Am J Clin Nutr. 2011;93(5): 1006-11.

28. Conesa-Botella A, Meintjes G, Coussens AK, van der Plas H, Goliath R, Schutz C, Moreno-Reyes R, Mehta M, Martineau AR, Wilkinson RJ, et al. Corticosteroid therapy, vitamin D status, and inflammatory cytokine profile in the HIV-tuberculosis immune reconstitution inflammatory syndrome. Clin Infect Dis. 2012;55(7):1004-11.

29. Krasowski MD. Pathology consultation on vitamin D testing. Am J Clin Pathol. 2011;136(4):507-14.

30. Chun RF, Liu PT, Modlin RL, Adams JS, Hewison M. Impact of vitamin D on immune function: lessons learned from genome-wide analysis. Front Physiol. 2014;5:151. 
31. Selvaraj P, Prabhu Anand S, Harishankar M, Alagarasu K. Plasma 1,25 dihydroxy vitamin D3 level and expression of vitamin d receptor and cathelicidin in pulmonary tuberculosis. J Clin Immunol. 2009;29(4): 470-8.

32. Rashid Ali MR, Parameswaran U, William T, Bird E, Wilkes CS, Lee WK, Yeo TW, Anstey NM, Ralph AP. A prospective study of tuberculosis drug susceptibility in sabah, malaysia, and an algorithm for management of isoniazid resistance. J Trop Med. 2015;2015:261925.

33. William T, Parameswaran U, Lee WK, Yeo TW, Anstey NM, Ralph AP. Pulmonary tuberculosis in outpatients in Sabah, Malaysia: advanced disease but low incidence of HIV co-infection. BMC Infect Dis. 2015;15(1):32.

34. Ralph AP, Ardian M, Wiguna A, Maguire GP, Becker NG, Drogumuller G, Wilks MJ, Waramori G, Tjitra E, Sandjaja, et al. A simple, valid, numerical score for grading chest $x$-ray severity in adult smear-positive pulmonary tuberculosis. Thorax. 2010;65(10):863-9.

35. Nowson CA, McGrath JJ, Ebeling PR, Haikerwal A, Daly RM, Sanders KM, Seibel MJ, Mason RS, Working Group of A, New Zealand B, et al. Vitamin D and health in adults in Australia and New Zealand: a position statement. Med J Aust. 2012;196(11):686-7.

36. Gupta RP, Hollis BW, Patel SB, Patrick KS, Bell NH. CYP3A4 is a human microsomal vitamin D 25-hydroxylase. J Bone Miner Res. 2004;19(4):680-8.

37. Sloan DJ, Mwandumba HC, Kamdolozi M, Shani D, Chisale B, Dutton J, Khoo SH, Allain TJ, Davies GR. Vitamin D deficiency in Malawian adults with pulmonary tuberculosis: risk factors and treatment outcomes. Int I Tuberc Lung Dis. 2015;19(8):904-11.

38. Witt KD, Jolliffe DA, Wang Z, Thummel KE, Timms PM, Griffiths CJ, Martineau AR. Vitamin D status improves following recovery from tuberculosis (Poster). Thorax. 2013;68 Suppl 3:A115.

39. Anand SP, Selvaraj P. Effect of 1, 25 dihydroxyvitamin $D(3)$ on matrix metalloproteinases MMP-7, MMP-9 and the inhibitor TIMP-1 in pulmonary tuberculosis. Clin Immunol. 2009;133(1):126-31.

40. Tostmann A, Wielders JP, Kibiki GS, Verhoef H, Boeree MJ, van der Ven AJ. Serum 25-hydroxy-vitamin D3 concentrations increase during tuberculosis treatment in Tanzania. Int J Tuberc Lung Dis. 2010;14(9):1147-52.

\section{Submit your next manuscript to BioMed Central and we will help you at every step:}

- We accept pre-submission inquiries

- Our selector tool helps you to find the most relevant journal

- We provide round the clock customer support

- Convenient online submission

- Thorough peer review

- Inclusion in PubMed and all major indexing services

- Maximum visibility for your research

Submit your manuscript at www.biomedcentral.com/submit 